\title{
LIBERDADE E AÇÃO NA TEORIA POLÍTICA DE HANNAH ARENDT
}

\author{
Eduardo Carlos Bianca Bittar \\ Doutorando pelo Departamento de Filosofia e Teoria \\ Geral do Direito da Faculdade de Direito da \\ Universidade de São Paulo \\ Samuel Rodrigues Barbosa \\ Doutorando pelo Departamento de Filosofia e Teoria \\ Geral do Direito da Faculdade de Direito da \\ Universidade de São Paulo
}

Resumo:

Uma proposta sobre a liberdade do exterior e a liberdade do interior, segundo Hannah Arendt, além de uma nova ontologia da liberdade. Esses são os temas abordados pelos autores que, neste trabalho, se esforçam para dirigir as idéias da filósofa de origem alemã e formação judaica, quanto ao aparecimento da liberdade extraída de seus textos sublimes, tais como "A Vida do Espírito" e "Entre o Passado e o Futuro".

\begin{abstract}
:
A proposal on the freedom of the exterior and the freedom of the interior, second Hannah Arendt, besides a new ontology of the freedom. Those are the themes approached by the authors that, in this work, they make an effort to drive the philosopher's of German origin ideas and Jewish formation, with relationship to the emergence of the extracted freedom of your sublime texts, such as "The Life of the Spirit" and "Between the Past and the Future".
\end{abstract}

Unitermos: liberdade exterior; liberdade do interior; ontologia da liberdade.

Sumário:

1. A proposta de Hannah Arendt; 2. A liberdade do exterior e a liberdade do interior;

3. Por uma ontologia da liberdade; Bibliografia. 


\section{A proposta de Hannah Arendt}

A liberdade é um fenômeno perceptível na vida comum: nos diretivos de conduta, na fabricação, na obediência e recusa à ordem. A legislação e a arte política com suas justificações parecem depender da existência da liberdade. ${ }^{1}$

Mas essa base comum, de certa intuição e evidência, apreensível pela experiência do comum dos homens, em nada assegura uma delimitação mais precisa da noção da liberdade, sempre de difícil delimitação. Assim, a tematização fundamentada e justificada de sua existência esbarra em várias dificuldades, a despeito de sua aparente evidência.

A fortuna das discussões históricas em torno do problema robustece ainda mais as dúvidas, o que aguça certo ceticismo para sua demonstração. Talvez, desde já, deva-se admitir seja a liberdade mais um termo metafísico, destes que não resistiriam a uma terapia mais acurada da linguagem - devendo a análise ser abandonada sem arrependimento. Mas uma suspensão de juízo sobre esse termo mysthicus significaria rejeitar apressadamente um terreno que assegura a própria tematização do Direito e, em termos mais amplos, de qualquer ação social. Daí a necessidade de encaminhamento da discussão para um campo sólido. Há, pois, fartas razões para tentar redefinir a noção da liberdade.

A proposta de Hannah Arendt não-prima nem pela abstenção de juízo e nem pela epistemologização excessiva da temática. Sua proposta é pôr em debate esse tema da metafísica política, e, com o enfoque que confere ao tema, sem dúvida, acompanha o dilema da erosão dos principais cânones erigidos pela tradição. De fato, a desarticulação das estruturas cristalizadas, constatada e declarada por Marx e por Nietsche, gerou um processo de ruptura entre o passado e o futuro, o que não é negligenciado por Hannah Arendt. ${ }^{2}$ Também tem-se presente que a questão da liberdade ganha atualidade com a irrupção dos eventos totalitários da primeira metade deste século, com ênfase para as experiências anti-semíticas nazistas, que absorveram o cidadão em uma estrutura ideológica sem medida, fazendo-o escravo e alvo do próprio Estado (Reich). ${ }^{3}$

1. Cf. Entre o passado e o futuro, 1972, p. 189.

2. Cf. Lafer, Da dignidade da política, Prefácio à obra de Hannah Arendt, Entre o passado $e o$ futuro, 1972, pp. 9-27.

3. Consulte-se a este respeito, da autora, a obra As origens do totalitarismo (The origins of totalitarism), e, também, Eduardo C. B. Bittar, La reconstruction des droits humains d'après Celso 
A autora procura, ao dissecar a questão da liberdade, dar cobro da noção historicamente construída que equaciona a liberdade ao livre-arbítrio. ${ }^{4} \mathrm{~A}$ ruptura com essa tradição só pode conduzir a especulação para o estudo da liberdade no seio das discussões políticas. ${ }^{5}$ O que a filosofia fez, e que Hannah Arendt procura desfazer, foi conduzir o debate acerca da liberdade a um solo pantanoso, tendo sido feito dela um atributo da vontade. Com isto, na crítica arendtiana, a liberdade foi deslocada de sua verdadeira sede: o campo político. ${ }^{6}$

É de se assumir, neste debate, que sem liberdade no espaço público, a todos garantida, não se pode verdadeiramente falar em liberdade. "Re-situando" a liberdade em meio ao público, porque o homem não-existe só e muito menos vive só, constrói-se ao nível da ação um nicho do agir conjunto. A ação é "re-conceituada" locus da liberdade, sede da mudança, sede da sempre perpétua ligação entre o que é e o que será (passado/futuro), sede do novo, sede do porvir, sede do aparecimento de novos eventos históricos, no incalculável do que ainda não é; o nicho do fazer é o da ação. Onde imperam a intersubjetividade, a dialogicidade e a comunicação deve se posicionar o estudo da liberdade. ${ }^{8}$

Mas essa "re-conceituação" da liberdade se dá após o salto de duas linhas de forças, as matrizes da discussão do problema da liberdade. Importa discutir esse duplo vetor, anotar uma perversão histórica da liberdade como vontade livre, para, por fim, decidir por uma pesquisa ontológica do problema da liberdade.

Lafer: points de repère pour l'étude de la problématique de la rupture totalitaire, in Revista da Faculdade de Direito da Universidade de São Paulo, v. 90, pp. 399-410, São Paulo, 1995.

4. "A liberdade, enquanto relacionada com a política, não é um fenômeno da vontade" (Arendt, Entre o passado e o futuro, 1972, p. 197).

5. "A raison d'être da política é a liberdade, e seu domínio de experiência é a ação" (Arendt, Entre o passado e o futuro, 1972, p. 192).

6. Cf. Arendt, Entre o passado e o futuro, 1972, p. 191.

7. "Sem um âmbito público politicamente assegurado, falta à liberdade o espaço concreto onde aparecer" (Arendt, Entre o passado e o futuro, 1972, p. 195).

8. "O campo da política é o do diálogo no plural que surge no espaço da palavra e da ação -o mundo público - cuja existência permite o aparecimento da liberdade" (Lafer, Da dignidade da política, Prefácio à obra de Hannah Arendt, Entre o passado e o futuro, 1972, p. 21). 


\section{A liberdade do exterior e a liberdade do interior}

A primeira linha de força já foi mencionada, trata-se da identificação da liberdade com o livre-arbítrio (liberum arbitrium), equação sugerida na Antigüidade tardia que conferiu ao tema da liberdade uma certidão de nascimento no corpus filosófico. Essa equação significou um desvio do tema da liberdade ao ser formulado como um atributo da vontade do sujeito, que poderia ser experimentada em solidão.

Na fortuna grega, a experiência da liberdade, embora fosse conhecida no terreno especificamente político, não estava integrada ao corpus filosófico. Não havia uma fundamentação filosófica. O bios do filósofo não era a vita activa, mas a vita contemplativa. ${ }^{9} \mathrm{Na}$ filosofia política aristotélica, por exemplo, o esforço de domar o acaso e a busca da autarquia da pólis está em dependência de um conceito de imitação que não estava na base da práxis política, mas já era uma noção especulativa com forte conotação teológica. ${ }^{10}$ Em Platão, e é Hannah Arendt que analisa o mito da caverna, o critério para o juízo político não é dado pelos negócios humanos, mas pela contemplação do ser que essencialmente é, a Idéia (ê̂dos). Em particular, a idéia de Bem, que servirá como padrão para a justa medida. Não se trata de dizer que a liberdade não era conhecida na Antigüidade, mas sim que somente adentrou ao quadro da história da filosofia tardiamente. " O filósofo não se compunha com a pólis que era o lócus da liberdade, do fazer político. Com isto, o problema da liberdade em si não foi tematizado. A liberdade, assim, se contextualizou em função de necessidades históricas que compeliram o seu florescimento filosófico.

Surge aqui, portanto, um flagrante conflito entre as noções de liberdade interior da filosofia e liberdade exterior da política, o que é a chave para a compreensão do dilema entre theoría e práxis em Hannah Arendt. ${ }^{12}$

9. Em outra passagem Hannah Arendt assinala-nos que: "À antiga liberdade em relação às necessidades da vida e à compulsão alheia, os filósofos acrescentaram a liberdade e a cessação de toda atividade política... (A condição humana, 1988, p. 23). É este, especificamente, o bem do otium, ou seja, a libertação das amarras políticas e domésticas.

10. Cf. Tércio Sampaio Ferraz Jr., La noción aristotélica de justicia, in Atlântica, Madrid, IIU166194, março-abril, 1969.

11. Cf. Arendt, Entre o passado e o futuro, 1972, pp. 204-205.

12. Excelente estudo, além daquele constante d'A condição humana de Hannah Arendt, sobre o problema do surgimento da dicotomia theória/práxis na Antigüidade, encontra-se em Werner Jaeger, 
Essas duas linhas, que são a fortuna da tematização sobre a liberdade dão a urdidura do texto. A perda operada com a passagem da Antigüidade para os períodos pré-medieval e medieval importou na criação de uma fissura não-superada nem pelos filósofos da consciência da Idade Moderna (Rousseau, Locke, Hobbes...), nem pelos filósofos metafísicos (Kant, Hegel...); a oscilação continuou a se operar entre a liberdade como vontade ou como razão prática. Da vivência política, de exterioridade, de agir conjunto, passou-se irremediavelmente para a consciência, para a vontade em conflito (quero-mas-não-posso de Paulo de Tarso), enfim, para a interioridade (quaestio mihi factum sum de Santo Agostinho).

O esforço teórico de Hannah Arendt vem no sentido de recuperar algumas destas perdas, "re-situando" o problema, na atualidade, em seu eixo. A liberdade é mais que atributo da vontade, "é na verdade o motivo por que os homens convivem politicamente organizados" (Arendt, Entre o passado e o futuro, 1972, p. 192).

Hannah Arendt anota que a emergência do conceito de liberdade como interioridade está ligada à derrocada da experiência política romana. A aceitação da liberdade de consciência coincide com certo refluxo da experiência política.

Posteriormente, ocorre uma reapropriação política da noção de liberdade. Isto se dá com a noção de soberania - uma espécie de hipérbole do livrearbítrio. Ora, a descoberta da vontade se deu ao mesmo tempo que a descoberta de sua impotência. Na distinção pauliana entre poder e querer, bem como na interpretação agostiniana da monstruosa faculdade que se desdobra em um querer e em um não-querer, percebem-se dois movimentos interiores ao homem, como se houvesse duas vontades presentes no mesmo ser. Essa duplicidade não se resolve pela própria faculdade da vontade. A solução dessa duplicidade desemboca na opressão que evita a paralisia do querer e não-querer. Há a certidão de nascimento da opressão, como coeva da liberdade, como interioridade. O problema da opressão é intrínseco e perene. O retorno à política desse conceito de liberdade relacionado ao querer vai aparecer na soberania. A política e a liberdade passam a referir-se ao sujeito, ao indivíduo que pactua o surgimento do Estado, por exemplo. Da mesma

Sobre el origen y la evolución del ideal filosofico de la vida: Apêndice I à obra Aristoteles, pp. $467-$ 515,1992 . Este texto situa o surgimento da noção de theoría a partir da interpretação pitagórica da experiência circense de expectação, ou seja, de observação das coisas, em contraste com a experiência ativa (práxis), participativa, que situa o homem como ser agente e não como observador. Consulte-se, ainda, o texto de Hans Blumemberg, Il riso della donna di Tracia: una preistoria della teoria, 1988. 
forma que um querer se sujeita ao outro, na vida política a obediência, ainda que racionalmente explicada, é condição para a liberdade.

A autora refuta a necessidade dessa derivação. "A famosa soberania dos organismos políticos sempre foi uma ilusão, a qual, além do mais, só pode ser mantida pelos instrumentos de violência, i.e., com meios essencialmente não políticos (p. 213)" Conceituar a liberdade como um querer que depende da submissão não pode instaurar a política. A violência é um expediente sempre necessário, o que mostra que a soberania como cimento do corpo político não garante a fundação da ação política. É preciso, portanto, renunciar à noção de soberania.

3. Por uma nova ontologia da liberdade

Tendo em vista estes dilemas, a autora vai explorar a articulação do problema da liberdade como vivenciada apenas no processo da ação e em nada mais. Será um retorno a Agostinho, mas não à matriz cristã que conduziria novamente à noção de livre-arbítrio (liberum arbitrium). Se dá um retorno ao Agostinho romano, que assiste à dissolução das instituições políticas romanas. Em sua obra final, The life of mind, a autora vai fundar esse retorno, que é um momento de iluminação arendtiano por excelência, na base de uma ontologia política romana, não-cristã. Com efeito, há em Agostinho um conceito de liberdade que não é problema da faculdade da vontade.

O homem é livre porque é um começo (initium). Há a referência a Agostinho: Initium... ergo ut esset, creatus est homo, ante quem nullus fuit. ${ }^{13}$ Enquanto o mundo e os seres foram criados do nada (ex nihilo), o homem foi criado após o mundo. Com a criação do mundo foi criado o tempo. O homem é após o tempo. É um início já no tempo. Sempre individualmente, ele é um início, e por isso é pessoa. É porque tem essa peculiaridade de ser criatura temporal, que sabe da sua morte, que conhece seu termo final. O animal é liberto da expectação da morte, avança eternidade a dentro, como jorram as fontes (Rilke).

Porque é um começo, o homem pode começar. A autora definirá a liberdade como a pura capacidade de começar. Trata-se de um começo não ex nihilo, mas de um começo a partir da ação, e da ação situada no terreno público.

13. Cf. Arendt, $A$ vida do espírito, 1993, p. 348. 
O esforço se dirige para preparar as condições do aparecimento da liberdade. O espaço concreto do seu aparecimento. E isto só é possível se se não aceitar o refluxo da interiorização da moralidade. A liberdade se dá na ação no mundo, na exterioridade. É aqui (na exterioridade), e não ali (na interioridade), que se a percebe, se a vislumbra, se a faz acontecer. A tematização da liberdade, nesses termos, é representativa de um olhar fenomenológico. Procurar a clareira para o quid da liberdade. E, na ação, aparece a liberdade com seu brilho.

Percebe-se ainda mais, da leitura de seus textos, que ganha ênfase o aspecto ético da conduta humana, que se lastreia na imitação, segundo a melhor tradição da Antigüidade. Há um estudo da virtude da coragem, nos moldes das descrições gregas do éthos humano. A liberdade está, para sua ocorrência pública, na estrita dependência de atos de coragem; coragem no início, no "re-início" na fundação, na revolução, no "re-começo" Em verdade, o que há é um esforço de construção de uma "cosmologia" política, com a definição dos milagres - a irrupção improvável no curso do tempo. Neste sentido, mencionam-se os milagres na natureza, como a vida; bem como os milagres da ação do homem, e este é o caso das revoluções. Dos milagres na história, ao menos, conhecemos o autor, é o homem.

Toda a discussão que ora se procura colocar em destaque redunda num momento de suspensão, e esta suspensão final corresponde à não-proposta da autora de enclausurar a liberdade teoricamente, pois se procura enfatizar que: "Somente os homens, por terem recebido o dúplice dom da liberdade e da ação, podem estabelecer uma realidade que lhes pertence de direito" 14

Assim analisado, abordado e discutido, o problema da liberdade em Hannah Arendt parece apontar para o que a própria autora aceita como postulado da liberdade, ou seja, para uma nova ordem (novus ordum seculorum), ordem esta que está entre as possibilidades humanas de construção do futuro.

São Paulo, maio de 1999.

Bibliografia

ARENDT, Hannah. Entre o passado e o futuro. Trad. de Mauro W Barbosa de Almeida. $2^{a}$ ed., São Paulo: Editora Perspectiva, 1972.

14. Arendt, Entre o passado e o futuro, 1972, p. 220. 
ARENDT, Hannah. A vida do espírito: o pensar, o querer e o julgar. Trad. de Antônio Abranches, Cesar Augusto R. de Almeida e Helena Martins. $2^{\text {a }}$ ed., Rio de Janeiro: Editora Relume Dumará, 1993.

A condição humana. Trad. de Roberto Raposo. $4^{\mathrm{a}}$ ed., Rio de Janeiro: Editora Forense Universitária, 1988.

BITTAR, Eduardo C. B. La reconstruction des droits humains d'après Celso Lafer: points de repère pour l'étude de la problématique de la rupture totalitaire, in Revista da Faculdade de Direito da Universidade de São Paulo, v. 90, São Paulo, 1995, pp. 399-410.

BLUMEMBERG, Hans. Il riso della donna di Tracia: una preistoria della teoria. Trad. de Bruno Argenton. Bologna: Il Mulino, 1988.

FERRAZ JR., Tércio Sampaio. La noción aristotélica de justicia, in Atlântica, Madrid, III/166-194, março-abril, 1969.

JAEGER, Werner. Sobre el origen y la evolución del ideal filosofico de la vida: Apêndice I à obra Aristoteles, Trad. de José Gaos, México, Fondo de Cultura Económica, 1992, pp. 467-515. 